\title{
La corta boca humana
}

\section{SERGIO RAMIREZ FRANCO}

A pesar del tiempo transcurrido, El cuerpo de Giulia-no ${ }^{1}$ todavía permanece como un palacio en la penumbra. Cuando se publicó, en 1971, la atención de crítica y lectores se dirigía predominantemente a los autores agrupados bajo el llamado "Boom" de la narrativa latinoamericana, amén de otros cuya notoriedad se había incrementado como consecuencia de habérseles incorporado, impropiamente en varios casos, a la novísima constelación de escritores. Para la literatura peruana, 1971 fue el año en que se editó la trágica novela póstuma de José María Arguedas: El zorro de arviba y el zorro de abajo. La coyuntura no era la más propicia para la novela que nos ocupa. Por lo demás, su autor, Jorge Eduardo Eielson, era desde varios años atrás un poeta instalado en una marginalidad sin aspapientos. La novela misma no parece ser, a primera yista, la clase de obra de la que se obtenga pronto provecho. Hasta el día de hoy se mantiene la misma distracción, la misma indiferencia. Comprobamos con escándalo que en una cronología de la narrativa peruana del año 1968 a 1983, que aparece anexa a una antología seria del reciente cuento peruano ${ }^{2}$, el estudioso no consigna El cuerpo de Giulia-no mientras que sí se toma la molestia de señalar que una recopilación de cuentos firmada por un escritor asimilado a lo que algún especialista en literatura latinoamericana denomina el "Boom Junior", merece una segunda edición. Lo curioso

${ }^{1}$ Jorge Eduardo Eielson, El cuerpo de Giulia-no. México, Joaquín Mortiz, 1971. Existe una traducción al francés: Le corps de Giulia-no. Paris, Albin Michel, 1980. Traducción de Claude Couffon.

${ }^{2}$ Nos referimos a la cronología preparada por Américo Mudarra Montoya, que aparece en la antología titulada Nuevo cuento peruano. Lima, Mosca Azul Editores, 1984. La antología fue preparada por Antonio Cornejo Polar y Luis Fernando Vidal. 
de este descuido general es que Eielson dista mucho de ser un desconocido en nuestro medio. No lo era al publicar su primera novela; menos lo es ahora, pues ya se le reputa entre los más importantes poetas peruanos del presente siglo. ¿A qué atribuir tan poca consideración hacia lo que él nos brinda? ¿A que se expresa a través de una forma distinta a aquella en la que se sustenta lo que se considera lo más significativo de su obra literaria? ¿A su exilio? Tal vez a todo y a nada. A todas las razones propuestas pero sin que ninguna de ellas sea por sí sola necesaria o suficiente. Otras trayectorias niegan los supuestos implícitos en cada una de las preguntas, todas las cuales son esencialmente ingenuas y por eso mismo útiles.

En el presente ensayo intentamos una primera aproximación a algunas de las características resaltantes de El cuerpo de Giulia-no. Nos interesa abrir la discusión; no cerrarla. En última instancia nos sentiríamos gratificados si lográramos despertar la curiosidad de los potenciales lectores que esa novela excepcional se merece.

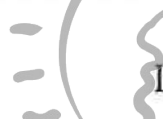

Las primeras reseñas que merecio El cuerpo de Giulia-no se deben a Héctor Manjarrez, Manuel Tarazona Espinoza y Juan Gustavo Cobo Borda $^{3}$. Los dos primeros abundan en metáforas y "Agudezas" que revelan con claridad un grado de desconcierto mayor ante el texto. Manjarrez apunta ingeniosamente que la novela en realidad es un cuadro. Aunque la afirmación es sugestiva, solo se sostiene gracias a la buena voluntad que uno ponga en "ver" el libro de esa manera. Cobo Borda intenta, con mayor esfuerzo, dar al lector una idea aproximada de lo que es el texto. Cita en su afán didáctico, a escritores tan disímiles como Braulio Arenas, María Luisa Bombal, André Breton, Novalis, y culmina indicando que la escritura de Eielson tiene bastante afinidad con la de Raymond Roussel.

Creemos que la mención de Roussel se explica por el hecho de que la novela usa como segundo epígrafe una frase de una de sus obras;

${ }^{3}$ Juan Gustavo Cobo Borda, "El cuerpo de Giulia-no". En: Eco, revista de la cultura de Occidente. Bogotá. Tomo xxv/5. Setiembre de 1972, pp. 555-558. Sin duda, el único texto rescatable de las tres primeras reseñas que tuvo la novela. 
y tal vez esté ligeramente justificada la referencia a Heinrich Von Ofterdingen de Novalis, texto con el cual tiene en común la tendencia a lo reflexivo y la atmósfera de ensueño, pero las demás comparaciones son desacertadas. Especialmente la que se hace con "Nadja" de Breton. Ni el temperamento, ni la temática, ni las opciones narrativas permiten establecer un paralelo justificable entre la obra del peruano y la del francés. Más allá de la incoherencia que supone declarar un texto como inclasificable y construir inmediatamente una serie de textos "raros" donde poder encasillar el texto indócil, no se ve para qué otra cosa podría servir la mención de tantos autores que no sea para confundir al lector.

A decir verdad, El cuerpo de Giulia-no facilita mucho su lectura. Por lo pronto, admite su adscripción a un género determinado: la novela. Un género, nos lo recuerda $\mathrm{Culler}^{4}$, es una instancia naturalizadora pues permite la decodificación al hacer factible la remisión del texto a una serie que activarâ expectativas y estrategias de lectura que pueden ser satisfechas $\sigma$ defraudadas. En la tapa posterior del libro encontramos una nota donde se resume el material temático de la obra y se asume la identidad de novela. Este elemento paratextual $l^{5}$ establece el contrato narrativo con el potencial lector.

Desde un comienzo,io decmode estrictamente funcional, relacionamos El cuerpo der Giulia-non cöndan "Novela de Formación" o "Bildungsroman". Se trata de una forma que entronca con el cronotopo de novela de biografía o de autobiografía grecorromana, en la que es fundamental la dinámica del tiempo como agente modificador del personaje principal; importa todo lo que resulte emblemático respecto a la vida del protagonista y al mundo en el que se desenvuelve, de ahí que se observe al sujeto a lo largo de varias etapas de su desarrollo existencial y de su ligazón con el universo, el cual deja de ser un simple decorado y se convierte en una instancia decisiva. Es un concreto, fijado en la historia y el héroe pierde su cariz abstracto.

${ }^{4}$ Jonathan Culler, La poética estructuralista. Barcelona, Editorial Anagrama, 1978, pp. $188-228$.

${ }^{5}$ Gérard Genette, Seuils. Paris, Seuil, 1987. 
Como ejemplos de "Novela de Formación" podemos citar Gargantúa y Pantagruel de Rabelais, David Copperfield de Dickens, Oblomov de Goncharov, El juego de los abalorios de Hesse. Hay algunas cuyo tema específico atañe a la esfera del arte. En esas novelas el tránsito del sujeto desemboca en la experiencia creativa. El retrato del artista adolescente de Joyce o En busca del tiempo perdido de Proust serían buenas muestras, $y$ en ese nivel es donde hay que ubicar la novela para una aprehehsión más justa ${ }^{6}$.

En todo relato se distingue dos niveles: el de la historia y el del Discurso ${ }^{7}$. La historia es una sucesión de acontecimientos tal y como estos acaecen en el tiempo y en el espacio. El Discurso, en cambio, consiste en la forma en la que tales acontecimientos nos son referidos.

El cuerpo de Giulia-no tiene como características inmediatamente perceptibles el ser narrado en primera persona, predominantemente del singular, utilizando el pretérito imperfecto y el pretérito indefinido y el hecho decisivo de que quien nara és el personaje que asume el rol protagónico en la ficción. En términos de Genette se trataría de un narrador "Autodiegético". Este narrador inicia su discurso en un momento de crisis: la mujer que ama ha muerto. La situación excepcional lo obliga a examinar sư vida. Ese fepasoes la novela, y acorde con el vaivén de la memoria tos hechos son recordados sin constreñirse a su secuencialidad lógico-temporal. El Discurso es un "puzzle"; su reordenamiento nos da la historia.

El narrador es consciente de su decir. Lo mide, lo cala, y, sobre todo, lo sabe fundante. Hay dos discursos: la novela y el proceso de la escritura misma de esa novela. El narrador nos confía en breves intervenciones que se percata de que la substancia de la "realidad" que él recrea es verbal; que todo lo que reconstruye se apoya en la insuficiencia de la palabra:

${ }^{6}$ M.M. Bajtin, Estética de la creación verbal. México, Siglo xxı editores, 1982, pp. $207-220$. 1971.

${ }^{7}$ Emile Benveniste, Problemas de lingǘstica general. México, Siglo xxI editores,

${ }^{8}$ Gérad Genette, Figures III. Paris, Seuil, 1972, pp. 225-267. 
"Pero mis palabras no podrán nunca formular ese vacío, puesto que ahora tu cuerpo mismo depende de estas palabras" (p.11).

Esta elección narrativa permite también la intensificación del dolor que sacude al protagonista, quien ahora solamente puede intentar hablar a una mujer a la que ya no alcanzan las palabras:

"¿Cuál sería el límite de nuestra cuantiosa sed, de nuestro agudo amor a la vida, a la libertad, a la salud? ¿Qué sucedería el día en que todo fuera conquistado? ¿Quiénes serían los culpables de nuestra sed aún insatisfecha?" (p.120)

El lector comparte el sufrimiento al ser tocado por una cadencia elegíaca, por un lamento que el relato analéptico agudizará cada vez que se quiebre ese discurso y se abra paso el del hombre solo, desvalido, que escribe para resarcirse de su pena.

\section{Consideremos el Cuerpo.}

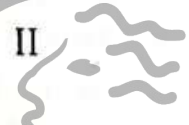

La obra es precedida por un epígrafe* tomado del libro del "Tao Te Ching" de Lao Tse', que reza así:

"Lo que hace que yo pruebe un gran dolor es que poseo

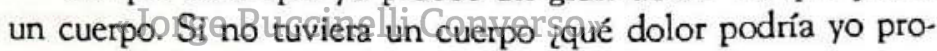
bar?

* No se ha considerado pertinente aludir a los otros dos epígrafes que se encuentran en la novela puesto que en lo esencial no alteran la dirección del sentido que implica el primero. Todos ellos corresponden a una búsqueda existencial de Eielson que desembocó luego en la asunción del Budismo Zen. Quizá uno de los textos en el que se haga explícita de manera más clara esa nueva orientación, sea "Eros/iones", texto que también muestra relaciones con el arte conceptual.

${ }^{9}$ Se trata de un fragmento del texto xill. Las traducciones son muy diversas e ignoramos cuál ha empleado Eielson. Lo importante es que se busca remitir a un sistema de pensamiento en el que se violan los principios aristotélicos. Para el Taósmo toda separación de espacio y tiempo carece de sentido. Para efecto de una comprensión mayor del tema véase:

Richard Wilheim, Laotsé y el Taoismo. Madrid, Revista de Occidente, 1926. Press, 1961.

C. K. Yang, Religion in Chinese Society. Los Angeles, University of California 
Detectamos un juego de sentidos con el verbo "Probar", el cual puede ser entendido, en un principio, en su acepción de la experiencia que se realiza de algo; y, en un segundo momento, conforme su acepción de testimoniar o dar razón de alguna cosa. Es la figura que en Retórica se conoce con el nombre de "Silepsis"10. El cuerpo de la persona permite la cognición a través de los sentidos y en sí mismo ilustra la prueba de esa aprehensión. La vivencia de nuestro cuerpo es interna, va de adentro hacia fuera; los estímulos externos reclaman que nos reconozcamos como un cuerpo. Hay que agregar: un cuerpo que no es permanente. El horror ante la muerte y la descomposición es uno de los ejes en El cuerpo de Giulia-no y lo encontramos en toda la obra poética de Eielson. Alcanza su mejor ilustración en mutatis mutandis ${ }^{11}$, texto que consideramos su poemario más compacto, entendiendo por compacto el perfecto ensamblaje de todos los recursos expresivos a un fin único que cuaja por completo. En la novela hallamos con frecuencia imágenes de plenitud y de descomposición, de decaimiento de lo físico:

"Un día, quizás, las hordas del cielo nos aniquilarían, se apoderarían de Mayana y yo sería incapaz de defenderla. La sangre de su vientre gotearía sobre mi cabeza, resbalaría por los muros, y yo no podría hacer nada. Nada. Una cuchillada sin fin pella quetse desangratía para siempre, que se llenaría de gusanos"."g(p. 23) tinelli Converso"

"Entre sus dos ojos verdísimos, la nariz recta y los labios bien diseñados le conferían un aire estatuario que contrastaba con la exuberancia tropical de su cuerpo y sus ademanes vivísimos. Me era imposible imaginarlo viejo, enfermo o cubierto de grasa". (p. 96)

Eielson, que nos ha dado el siguiente verso: "Justicia del gusano, mal paraíso"12, podría hacer que su personaje nos cantara la canción de Ariel: "Sus huesos se han hecho coral y sus ojos perlas. Nada de él ha de perderse sino que se transmutará en algo opulento y extra-

${ }^{10}$ Para un empleo interesante de esta figura, pues se le da aplicación estructural en el análisis, véase: Tzvetan Todorov, Poetique de la Prose. Paris, Seuil, 1971. 1976.

${ }^{11}$ Jorge Eduardo Eielson, Poesía escrita. Lima, Instituto Nacional de Cultura, ${ }^{12}$ Op. Cit. p. 73. 
ño $^{13}$. El mismo horror que busca ser exorcizado mediante la plasticidad de la imagen y la suntuosidad de la metáfora delicada. La muerte se conecta con la merma del espacio:

"Millares de naranjas podridas cubrían el suclo de una alfombra áurea y pestilente" (p. 94)

"Venecia salobre, pestilente. Venecia vacía, hundida en las aguas fangosas, cubierta por un sudario blanco. Aguas podridas, cielo podrido, palacios de cristal podrido, roída por los turistas, manchada de mercaderes, de aceites putrefactos, de gases venenosos" (p. 44)

El cuerpo es también el cuerpo del otro. El cuerpo del ser amado o deseado. Eduardo, el protagonista, quedó marcado por la imagen de Giuliano cuando ambos eran adolescentes, y su lealtad yace anclada en el pasado, junto a las líneas puras del joven que nunca permitieron presentir la horrorosa metamorfosis en un individuo vulgar, vil, corrupto. La pasión por la mujer análogamente pertenece al pasado y quedó viciada por la duda, la ambiguedad, la impostura. Entre la prostituta y el burgués se tiende un mismo arco de degradación del que hablaremos adelante.

La percepción del otro (a la inversa de lo que ocurre con la que tenemos de nosotros trilshio) se digigeptineetoassu inmediatez física como totalidad, no comp fragmento.] ELotroces una superficie. Como la de una espejo: su mirada nos constituye y así nos demuestra cuán ilusa es nuestra autosuficiencia ${ }^{14}$. Si bien el recuerdo de Giuliano permanece al abrigo de la mengua que sufre la persona, ello no impide la aflicción por la caída:

" ¿No lo verás nunca como yo lo vi una sola vez: mezcla monstruosa de muchacho y de pájaro sagrado, a orillas del Tulumayo, en aquel atardecer rojizo e instantáneo como un fogonazo? ¿Por qué no era él como Mayana, inalterable en mi memoria, indemne de toda mancha, de toda abyección humana?" (p. 20)

${ }^{13}$ William Shakespeare, The Tempest. New York, The Signet Classic Shakespeare, New American Library, 1964, p. 56.

${ }^{14}$ Jacques Lacan Ecrits. Paris, Gallimard, 1966. 
El amor por Giuliano es esencialmente erótico. El amor por Giulia es apocalíptico, lleno de altibajos violentos en los que aflora el componente tanático. Habría una contaminación anal en ese afecto, para emplear terminología proveniente del psicoanálisis ${ }^{15}$. El mejor ejemplo es el siguiente:

"Nada, Dogaresa, nada pudo servir mejor a mi intolerancia por los demás que tú misma, delante de mí, en el papel de suma sacerdotisa de mis deseos y de mis sueños. A fuerza de buscar la luz hubiera podido devorarte un seno, y tú habrías sufrido de esa llaga incurable como de una enfermedad dulcísima, sin lamentarte" (p. 87)

En última medida, al protagonista no le queda otra cosa que tratar de superar las limitaciones que el universo fáctico impone a sus deseos de plenitud apelando al ensueño, a la contemplación, a la vivencia plena de cada momento, en el que podría estar acechando una revelación:

"Toda mi vide pasada y futura se arremolinaba alli ahora. Las cortinas abiertas me invitaban a volar. Dos alas inmensas rebalsaban de la cama. Me pesaban a la espalda. Suntuosas alas de plumas áureas, tornasoladas, bermellón, naranja. Cualquier vuelo sería posible con ellas. Cualquier misterio se acabaría al instante" $($ f.:81)

La glorificación del instante, la inminencia de la epifanía ${ }^{16}$ explican la resuelta fragmentación que asume el discurso: muchas escenas están "descompuestas" en sus elementos mínimos. La novela de Eielson podría ser definida como "Minimalista"; como descriptiva antes que narrativa. La descripción puede jugar dos papeles: uno, conforme a la tradición y a la Retórica, es el de ornar el discurso retardando la exposición; el otro, que aparece hace unos 200 años, funciona como elemento de la diégesis misma aportando símbolos y explicaciones ${ }^{17}$. En El cuerpo de Giulia-no, la descripción consigue minar la ilusión

${ }_{16}^{15}$ Sigmun Freud, Obras completas. Madrid, Biblioteca Nueva, 1968.

${ }^{16}$ Es este concepto el que vincula más el texto a la Tradición, en el sentido que da a esta palabra Rene Guenon.

${ }^{17}$ Gérard Genette, "Fronteras del relato". En: Análisis estructural del relato. Colección Comunicaciones, dirigida por Eliseo Verón. 
naturalista debido al exceso de precisión. Compone una cadencia ritual que excluye toda vivacidad y desparrama a lo largo del texto indicios ${ }^{18}$ que conforman una gran cadena semántica sólo descifrable al integrar todos los componentes en un único sintagma.

La cosmovisión de la novela es Romántica. Los hechos son distorsionados -lo asumiremos por el momento- debido a la sensibilidad lírica de Eduardo. Decir distorsión al referirnos a una asimilación lírica del mundo es, sin duda, una redundancia. La lírica no es un género; es una forma de transgresión de los diversos esquemas discursivos que rompe la linealidad y se constituye en un anti-discurso al amplificar las potenciales referencias a un número indeterminado de contextos posibles con una máxima condensación verbal ${ }^{19}$. La constante fuga del discurso hacia otros ámbitos puede desconcertar a aquellos lectores que añoran las novelas en las que el tiempo era un buen navío, pero para quienes estén formados en la tradición lírica de los últimos 200 años o sólo en la novela contemporánea no debería haber motivo de confusión al leer la novela de Eielson.

Por último, con respecto al cuerpo ocurren dos cosas que no podemos obviar: la primera es que existe una marcada tendencia a presentarlo abandonado a la mera sensación y por eso el efecto se diluye a lo largo dejaiobra;te esegundo quenpasa es que al acudirse siempre a metáforas y símiles guen involucran en, sus polos comparativos la totalidad del universo, hay un debilitamiento del poder representacional. La excesiva abstracción impide fracturar el "automatismo de la percepción"20 del cuerpo; éste es nombrado asiduamente pero nunca construido y, al escoger mencionarlo antes que construirlo, catalogarlo y no configurarlo, se frustra una nueva captación. De más esta decir que no se logra conmover ni sugerir mucho.

${ }^{18}$ Oswald Ducrot y Tzvetan Todorov, Diccionario enciclopédico de las ciencias del lenguaje. México, Siglo XXI editores, 1989, pp. 104-109.

${ }^{19}$ Susana Reisz de Rivarola, Teoria Literaria. Lima, Pontificia Universidad Católica del Perú, 1987, pp. 119-132.

${ }^{20}$ Tzvetan Todorov, Teoría de la literatura de los formalistas rusos. Buenos Aires, Signos, 1970. 
Lo que comienza como lamento y una rebelión personal trasciende la esfera de lo individual para lanzarse a un cuestionamiento del universo entero por ser un "mal paraíso" -ya no es solo la "justicia del gusano": es la hegemonía de sistemas corruptores de la inocencia humana $y$, dicho de forma terrestre, la degradación de millones de seres humanos por un sistema socio-económico que los osifica en vida luego de postergarlos racialmente y de haber detenido el flujo de sus culturas en su desarrollo autónomo. Contra la posibilidad de relaciones humanas justas y sinceras, plenas y en que exista lugar para la contemplación de la belleza en todas sus manifestaciones para la belleza misma, conspiran las relaciones de dominación y dependencia que son enfocadas con precisión desde un espacio historizado, sin asumir jamas un falso universalismô que, además de inútil, suele ser en la práctica una forma astuta, o ingenua, según se le mire, de complicidad.

Pancho y Mayana no son una pareja de "buenos salvajes". Encarnan la posibilidad de superar un estadio de expansión del capitalismo en el que, junto con el dinero que ahora penetra y circula por todo el mundo, intenta homogenizar culturalmente a los pueblos, de manera que reciclen los hábitos consumistâs y nề desafíen el poder. Tal es el sustrato de la noción hae "Fin de la Histofia".

Hemos dicho posibilidad y quizá haya quien no lo entienda así, una vez concluida la lectura de El cuerpo de Giulia-no. ¿Posibilidad esos seres vejados y sumisos, al parecer resignados al rol de servicio y producción que se les ha asignado?

Toda sumisión es causada por un excedente de opresión, y ese estado no puede durar por siempre, de modo que vislumbramos un intento de conquistar la hegemonía para escapar a un sistema que puede incorporar a quien se convierta, y no es impreciso el verbo, a Occidente. La novela repite escenas de una misma película, la de la "Conquista del Perú" y recalca el rol desintegrador de las identidades tradicionales por obra de la Iglesia. No es para nada gratuito que se acuda a una forma moderna de reproducción de la realidad, precisamente aquella en la que el referente, mediante la fotografía, no puede 
ser escamoteado ${ }^{21}$. Pero, a la par que ello, el cine niega la noción de original y en su lugar exhibe el vértigo de la reproducción al infinito. Las escenas no se repiten pero se asemejan demasiado; la degradación se reitera y tiende a borrar o reducir casi hasta cero las diferencias. Un único universo que no admite la alteridad, sea ésta social, cultural, racial o sexual. El formidable capítulo noveno lo expresa desencadenando una brevísima anti-utopía que habría deleitado de pavor a Zamiatin, Orwell o Huxley:

“¿Cuánto podrá valer una chuncha en el año 2000, en las grandes ciudades lunares? Serás pagada entonces, inocente [...] Recibirán tu sangre en un bocal de plexiglas y ya no serás peruana ni chuncha ni nada. [...] Tendrás un hijo al costo irrisorio de 600 dólares ejemplar. LBM112 decidirá el color de sus ojos. Su estatura colosal. El ritmo de sus arterias. Su mentalidad infantil. Será astronauta. El tío Miguel, todo vestido de blanco, con guantes y máscara transparente, lo enviará a la Base Experimental Cafetera de Venus. ¿Es acaso el hombre el único consumidor de café en este mundo? [...] Ahora tu vientre no es sino un depósito de huevos blancos. Huevos de astronautas rubios, de ojos azules y cerebro de canario. La esperma miserable llena el cielo de ángeles sin alma. La voz canalla te persigue. Voz eléctrica de computadora que no cesa. La serie ha comenzado. Triadas de cashibos alternadas a parejas de cámpáse y amueshall. Millares y millares cada año, consumidores de millares y millares de automóviles, refrigeradoras, televisores, máquinas de cocinar, de lavar, de conversar. (p. 49)

Ante el avance deshumanizador, la novela opone la utopía:

"Los hijos de Pancho y Mayana crecerán felices.

Se acabarán las guerras, la explotación, la injusticia.

Desaparecerán el hambre, las enfermedades, la miseria.

Poco a poco se alejará la muerte hasta casi desaparecer.

Lloverá finalmente sobre Lima.

Venecia será salvada de las aguas.

Reinará el amor sobre la tierra. (p. 137)

${ }^{21}$ Roland Barthes, La cámara lúcida. Barcelona, Paidós, 1990. 
Pero es apenas un espejismo tolerado por el lenguaje lo que lleva al protagonista a decir "¿Para qué engañarte con más y más palabras dispuestas siempre en el mismo orden pálido y mezquino?" Sin embargo, esa revuelta en la que un grupo de indios desciende de una astronave a Italia y acaba con ciudad y habitantes, promete la posibilidad de otra modernidad y de otra cultura que reten la de Goethe y Petrarca, cuyas efigies son destrozadas por la horda invasora.

\section{IV}

Giulia y Giuliano -quien, de acuerdo al narrador es "Giulia con ano"- se contraponen a Pancho y Mayana (Mañana). Los dos primeros no serán pareja pues su función simbólica es la de proclamar la imposibilidad de reconstituir el andrógino primordial. Están en uno de los extremos del arco de la degradación capitalista. Por el otro lado, la violada y el sumiso; pero eśas condiciones son temporales y pueden trastocarse. La dualidad funciona en toda la novela para remarcar su artificialidad con un binarismo abundante. Dualidad de roles, dualidad de espacios, reiteraciones; de lo que se trata es de romper el Realismo. Entendemos por Realismo un paradigma cognitivo que deriva de una cottiente tieeraria desaftollada en Europa durante un período que casi Mege Q Q coincidirCenterariente con el del siglo pasado; este paradigma finca el valor de un texto ficcional de acuerdo a su remisión y fidelidad reproductora de lo que se entiende que constituye la realidad. No está de más recordar que jamás se parte de una definición previa de la realidad. A partir de ello, podemos empezar a cuestionar la pertinencia del reflejo como criterio valorativo. Ya el Formalismo Ruso ${ }^{22}$ señalaba la paradoja de que toda nueva escuela literaria recuse a la anterior por su alejamiento de la realidad, lo que vendría a corregir la nueva tendencia que, a su vez, será negada por la que le suceda con el mismo argumento.

Barthes ${ }^{23}$ señala el común punto de partida que es el de considerar como ciertos los significados que tiene toda oración, es a partir

${ }_{22}^{22}$ Op. Cit., pp. 21-54.
${ }^{23}$ Roland Barthes, S/Z. Madrid, 1980. 
de que se asume mediante los contratos narrativos la validez de un hablar específico que los semas se unifican en torno a una entidad ficticia; la del sujeto. Una vez realizada esa operación, diferentes recursos retóricos y estilísticos provocan la ilusión a un mundo posible ${ }^{24}$ que necesariamente ha de apoyarse en la previa comprensión del mundo fáctico, de donde se tomarán instrucciones para adecuar a ellas los actos de habla. Perlocutivamente el lector es empujado, generalmente, a identificar el mundo propuesto con el universo en el que se desarrolla su existencia y la de los suyos, con algo que podría identificarse con la estructura que el mundo tiene. Tal ligazón, profundamente arraigada en los hábitos del lector promedio, empobrece la percepción del mundo al negarse a dotarlo de pluridimensionalidad, característica connatural que posee. En la renovación Vanguardista de la narrativa latía la subversión del Realismo. De forma agresiva en Joyce y Kafka, y buscando agotar todas sus posibilidades en el caso de Proust. Mann intenta con pleno éxito una simbiosis de formas tradicionales y nuevas. La negativa a colocar en primer plano la trama, la disolución del personaje en su rol actancial o en la mera verbalidad que lo constituye, la ilustración del proceso mismo de escritura, que no recubre sus estructuras sino que las ostenta, todo esto tiene claros antecedentes en la tradición del mismo-Occidente.

Ha tenido que llegarse a un momento de claro agotamiento formal y de debilitamiento del proyecto de la Modernidad para que sea posible y productivo rescatar autores y textos que la tradición de la novela, capturada por la burguesía ${ }^{25}$, expulsó para poder hacerse de soportes ficcionales a su concepción del mundo. En El cuerpo de Giuliano escuchamos ecos de Sterne, de Diderot; notamos cierta coincidencia con el proyecto escritural del "Nouveau Roman"26, y tal vez por todo lo dicho sea que no nos interesó; que nos interesó que pasara desapercibida ya que no sabíamos muy bien qué hacer con ella, dónde colocarla, junto a cuáles otras novelas. Nuestra magra tradición novelísitica se funda en el Realismo, que funcionó entre nosotros de

\footnotetext{
241 .

${ }^{24}$ Umberto Eco, Lector in fabula. Barcelona, Editorial Lumen, 1981, pp. 172.

${ }_{25}^{25}$ Julia Kristeva, Semiótica. Madrid, Editorial Fundamentos, 1978, 2 vols.
${ }_{\text {Ludovic Javier, Una palabra exigente. Barcelona, Barral Editores, } 1972 .}$ 
modo diverso a como ocurrio en Europa, donde la burguesía floreció completamente. Aquí, fue un espacio de combate entre tendencias modernizadoras de la sociedad y tendencias reaccionarias; la propaganda antes que otra cosa fue el humus nutricio de la novela. Si observamos con cuidado veremos que hasta un experimentador con Vargas Llosa es conceptualmente casi tan anacrónico como Balzac o Stendhal, que su idea de relación entre ficción y verdad pasa por el criterio del Mímesis, en un movimiento confuso que ora lo niega, ora lo reclama. Distinto por completo es el caso de Eielson. No intenta una imposible reproducción de la realidad. Por el contrario, la sabe inaprensible salvo por sus efectos y por las inferencias que a partir de ella podamos efectuar.

El juego de referencias significantes que constituye el lenguaje $\mathrm{e}^{27}$ es el tema esencial de la novela. El tránsito desde una confianza todavía fuerte en el lenguaje hasta el reconocimiento doloroso de su incontrolable polisemia y, como corolario, la tentación de hundirse en el silencio, en el vacio atisbado como espacio incontaminado por las marcas de un discurso que nos exceda.

Para identificar la originalidad de El cuerpo de Giulia-no conviene que volvamos sobre la noción, empleada páginas atrás, de "naturalización". Toda natualiząción se sirue de determinados marcos o "frames" 28 , son elementos portadores de un saber sobre el mundo que permiten actualizar los saberes convencionales del desarrollo del eventos entendidos como posibles, normales o necesarios, por lo tanto gracias a ellos puede darse la comprensión y el desempeño. La novela propone un primer marco al cual tendría que aproximarse el lector para decodificarla, ese marco totalizante está dado por el contrato narrativo que liga el texto a un género dentro del cual, y, sobre todo, gracias al cual, se le puede leer. Nosotros hemos entendido funcional acudir a otras instancias naturalizadoras con la clase de la "Novela de Formación", que nos parece la más productiva, pero nunca perdimos de vista

27 Jacques Derrida, De la gramatología. México, Siglo xxI editores, 1986, pp. 12-15.

${ }^{28} \mathrm{H}$. Gardner, La nueva ciencia de la mente: Historia de la Revolución Cognitiva. Buenos Aires, Editorial Paidós, 1987.

Teun A. Van Dijk, Estructuras y funciones del discurso. México, Siglo XXI, 1986, pp. 33-35. 
nuestra motivación estratégica. "El cuerpo de Giulia-no" trabaja sobre la defraudación de esquemas y espectativas. ¿Cómo así? Lo hace acudiendo basicamente a tres niveles: Lo incoherente, lo farsesco, lo maravilloso.

El texto aparece lleno de incoherencias. Se inicia con lo que podríamos denominar "falsa pista", ya que la novela parece construirse a partir de la resolución de un enigma: La muerte de Giulia. Ese enigma nunca es aclarado, pero entretanto nos hemos percatado de que es irrelevante. La escritura ya nos condujo a otra cosa.

El interrogatorio (capítulo octavo) es un modelo de realismo. Establece con eficacia en el diálogo las distancias ideológicas entre el comisario y Eduardo; los roles que cada uno cumple en la sociedad. Lo farsesco aparece cuando esa naturalidad de la ficción, esa conformidad que exhibe para el mundo según cánones comunes de conceptualización, se rompe por la irrupción de lo grotesco, de lo que Auerbach llamaría "Realismo criatural". Esas descripciones terribles de la iniciación sexual de Giuliano, en las que acudimos a un rito en el que la inmundicia sirve para el culto. Lo encontramos en la gestualidad estúpida del tío Miguel, el constante sumir la panza de Giuliano, la zumba del chofer y, entroncando con lo incoherente, el capítulo 19, en el que todos los personajes se dan cita en una inverosímil escena, muy teatral. Cada cual resume en una pequeña intervención su papel en la novela; cada cuallega portando los elementos que los caracterizan. Hasta el comisario, cuya aparición se motiva con un pretexto tan baladí que resulta ridículo.

Lo maravilloso es el nombre que damos, por ahora, a lo que en un momento tratamos de explicar, esto es de naturalizar, apoyándonos en la subjetividad del personaje, en su visión lírica del mundo. No es que no sea una explicación válida la que tentamos, ocurre que el texto la echa por la borda. Ejemplo de lo maravilloso es la imagen del chiwaco que se "desprende" del afiche y escapa de la curiosidad torpe de los "americanos"; las transfiguraciones de Giulia en pájaro; el encerrarse con la luna en el baño; en un pasaje notable que situaremos antes de cita: Eduardo es joven y ha llegado a la Oroya en un taxi fletado para él. Ha descendido y un grupo de indios salidos de las minas lo rodean. $Y$ ocurre lo siguiente : 
"Uno de ellos acercó su rostro a mí. Sus ojos brillantes reflejaban una habitación en desorden: cortina rojiza, lámpara amarilla y una cama revuelta en la que yacía yo con los ojos abiertos. Un olor a aguardiente e inmundicia invadió la habitación. Yo me levanté de la cama, me dirigí hacía la ventana y la abrí." (p. 86)

Una lectura que busque naturalizar el texto verá en él una traslación factible por la dinámca de la evocación desde la cual se dirige el discurso, se pensará en la técnica del embrague, se hará, en fin, cualquier cosa con tal de no romper el principio aristotélico de no contradicción. Lo que viene a decirnos Eielson es que la aventura empieza exactamente en esa transgresión; el texto, al asumir el poliestilismo, evita ser recuperado para la Institución literaria que ha dispuesto para él ciertos casilleros, como el de Literatura Fantástica o el de Real Maravillosa. Consigue romper los hábitos lectivos con la plena asunción de todos los posibles-semánticos y rompe su propio código con la misma facilidad con la que lo reasume, para, con esas fugas, recalcar la artificialidad del sentido que depende de su contextualización, pero contextualizar es enmarcar $y$, por muy preciso que sea el marco, jamás se podrá impedir que la semanticidad lo desborde ya que el significado mismo se transforma según la cadena sintagmática a la que este integrado. Ocurre que todo decir se ha tratado siempre de "soportar tenila presenciar supuesta de aquel que emite el discurso. La escritura es el lugar donde se desmiente esa metafísica de modo más contundente, pero ni siquiera aquel que se habla a sí mismo está en contacto directo consigo mismo ya que debe pasar por la mediación de los signos, lo que implica diferencia y, por lo mismo, la presencialidad de una ausencia, la de los téminos preteridos al constituir la cadena de sentido que sí se manifiesta; es decir que jamás se podrá arribar a una significación "fija" donde se detengan los sentidos potenciales. El contexto no permite regular la semiosis puesto que todo contexto puede ser subsumido en una serie más amplia ${ }^{29}$.

¿Qué ocurriría si entendiésemos como literales todos los pasajes que tendemos a naturalizar? Si trataramos de "unificar" las incoheren-

${ }^{29}$ Jacques Derrida, La escritura y la diferencia. Barcelona, Editorial Anthropos, 1989, pp. 382-385. 
cias sin limar las contradicciones entre ellas e integrarlas en un todo orgánico ipodríamos hacerlo? $\mathrm{O}$, para plantear otra pregunta, si un lector concluyera la lectura de Un mundo para Julius ¿Podría reconciliar las "dos conversaciones" que sostienen Julius y Bobby y asumir ambas como verdaderas en un mismo nivel ontológico? ¿No hemos incurrido en una contradicción al nombrar la operación anterior con el vocablo "reconciliar"? Tal vez no.

Las limitaciones del lenguaje tratan de ser superadas por el protagonista mediante candorosas operaciones:

$$
\text { "Giulia + No - Giuliano + Yo = Giulia" (p. 120) }
$$

O a través de superposiciones que indagan nuevos verbos: "Amodiar", "Odiamar". Hasta llegar finalmente a explotar las numerosas posibiidades de la combinación de palabras. La combinatoria es el inicio del vacio, la inutilidad que lleva a Eduardo a crear su propio sistema semiótico basado en relaciones de homología entre conceptos y nudos de colores asimilables a los "quipus", es una renuncia a la comunicación ingenua. También al entusiasmo.

La desconstrucción que Eielson emprende está en contradicción con su poética explícita ${ }^{30}$, lo cual sorprende pues el planteamiento de la novela es muy lúcido. La suya es una posición estética que ubica al sujeto en un espacio central, privilegiado, concibiéndolo como entidad capaz de aprehender el mundo, al cual se le concibe como cargado de sentidos previos cuya esencia, más allá de la memoria y los nombres, permanece inalterable. Mediante la poesía es posible acceder al conocimiento, siempre turbador, de la belleza que no se marchita y está desparramada por todas partes. Fiel a su designio creador, Eielson ha combinado la escritura con otras varias formas: la pintura, la escultura, la performance, el teatro. En todas ellas aparece la poesía, que es una

${ }^{30}$ Roland Forgues, "La creación como totalidad". En: Cielo Abierto. Lima, vol. $\mathrm{XI}, \mathrm{N}^{\circ} 32$, pp. 18.25 .

Roland Forgues, Palabra viva. Lima Librería Studium, 1988.

Abelardo Oquendo, "Eielson: remontando la poesía de papel; una entrevista". En: Hueso Húmero. Lima, N 10 , pp. 3-10.

Jaime Urco y Alfonso Cisneros Cox, "Jorge Eduardo Eielson: El creador como transgresor". En: Lienzo. Lima, № 8, pp. 189-205. 
sola y la misma y que con ninguna de ellas se identifica, así como una bailarina nunca se confunde con los tules que la visten. En todo caso, la contradicción insufla vida a la marmórea perfección de lo que Eielson hace.

(Nota de Redacción. Este trabajo fue el ganador, en el género "Ensayo", de los "Juegos Florales Universitarios" que convocó la UNMSM en 1992, en Homenaje al Centenario de César Vallejo. Se publica en Letras en cumplimiento de las bases de dicho certamen).

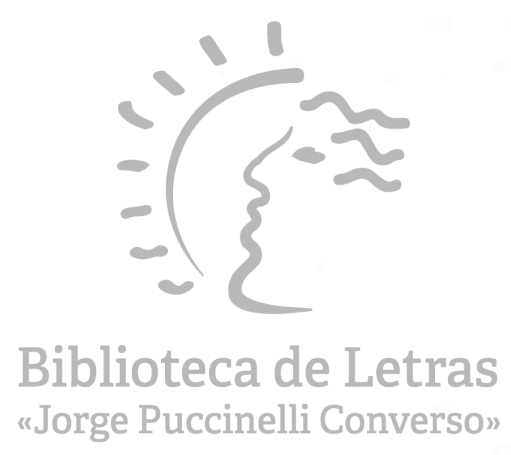

